\title{
Nanotechnology in Healthcare: Applications and Challenges
}

Suprava Patel ${ }^{*}$ Rachita Nanda and Sibasish Sahoo

Department of Biochemistry, All India Institute of Medical Sciences (AIIMS), Raipur, Chhattisgarh, India

\begin{abstract}
In this era of nanoscience, advances of nanotechnology have led to the creation of new generations of nanostructures, each characterized by their explorative utilization in various types of applications in biomedicine and bio-engineering. These applications are expected to significantly improve the diagnosis and therapeutic aspects of many diseases. The materials have been explored and reported as components of biosensors and as very efficient drug delivery platform. Though, few nano-materials have been reported to be used in clinical medicine, but not coherently effective. This could be because of nano-toxicity which is a potential limitation for its use in biological system. A brief description on the development of nanostructure for biomedical application over the years in terms of new materials and understanding of their interaction with the body, may lead to better biocompatible nanostructures.
\end{abstract}

Keywords: Nanotechnology; Health care application; Nanotoxicity; Challenges

\section{Introduction}

Nanotechnology and science of nanomaterials provide apt potential in engineering of materials and at present is the enormously growing and developing scientific technology. It is defined as the study of controlling, manipulating and creating systems based on their atomic or molecular specifications [1]. As stated by the US National Science and Technology Council, the essence of nanotechnology is the ability to manipulate matters at atomic, molecular and supra-molecular levels for creation of newer structures and devices [2]. Generally this science deals with structures sized between 1 to 100 nanometer (nm) in at least one dimension and involves in modulation and fabrication of nanomaterials and nanodevices. It has been endured as an area of intense scientific research in various fields like optical, electronic and biomedical fields. Bacterial cells, plant cells and mammalian cells which are more than $100 \mathrm{~nm}$ size can easily engulf or internalize the particulates of nano-size like viruses $(75-100 \mathrm{~nm})$, proteins $(5-50 \mathrm{~nm})$, nucleic acids ( $2 \mathrm{~nm}$ width) and atoms $(0.1 \mathrm{~nm})$. If we compare a single human hair diameter $(50 \mu \mathrm{m})$ to $1 \mathrm{~nm}$ nanofibre, hair will be 50,000 times larger than the size of $1 \mathrm{~nm}$ [3]. The great visionary late Nobel Physicist Richard P Feynman first designed the idea of molecular manufacturing in 1959. The legendary scientist who first suggested that devices and materials could someday have atomic specifications and that this development path cannot be avoided [4]. For years this science have engaged scientist in exploring the very unique physico-chemical properties of nanoparticles.

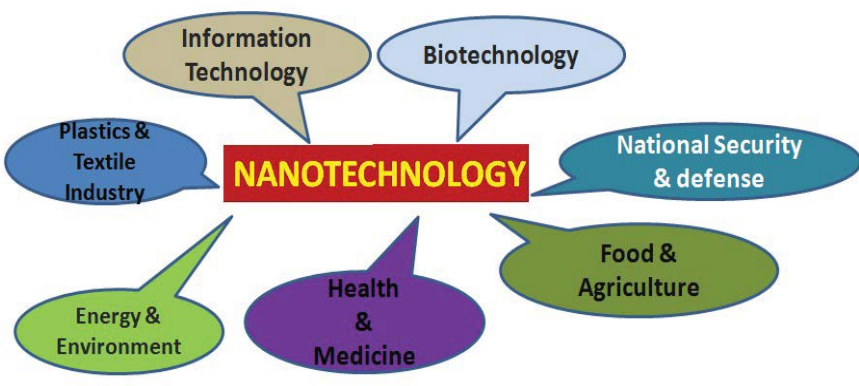

Figure 1: The diagram depicts the applications of nanotechnology in various research fields. Nanotechnology spans many areas like biotechnology, national security and defense, food and agriculture, information technology, aerospace, plastics and textile industries, energy and environment, cosmetics and health and medicine (Figure 1). In this review, the health care benefits and risks of nanomaterials would be enlightened along with their limitations and challenges for their applications in medicine.

\section{Perspectives of Nanotechnology}

\section{Applications in Medicine and Health}

Nanotechnology has potential to remarkably affect the diagnostic and therapeutic approach for a disease. The unparallel sensitivity and performance, enhanced durability and flexibility, unique physicchemical properties of nano-materials, have been exploited in medical diagnosis (Table 1) for early detection of diseases, in target approached clinical therapy (Table 2) and in regenerative medicine for reconstruction of damaged tissues.

\section{Medical diagnostics}

The entire world has witnessed the phenomenon revolution in biosensors towards Point-of-care testing by glucometer for blood glucose monitoring. It has developed from very primitive enzyme based method to amperometric based principle and further development of reverse iontophoresis method. The technique has evolved from invasive procedure to non-invasive monitoring, from in-vitro diagnosis to invivo monitoring of blood glucose.

Similarly many nano-devices and nano-biosensors have been innovated to monitor the bio- molecules, at a very low concentration resulting in detection of disease at an early stage. They can be a novel and powerful tool for cancer detection system. The traditional diagnostic modalities are unable to detect tumors in their initial stage and more imprecise in differentiating benign from malignant stage. Compared to the conventional methods, novel nanoparticles (NPs) are capable of yielding selective imaging of affected areas.

\section{Clinical therapy and drug delivery systems}

The innovative NPs not only act as efficient imaging agents for identifying the diseased tissues but are also ideal carriers to deliver anticancer drugs and other therapeutic drugs at the target site with optimum proficiency and minimum collateral damage to the

*Corresponding author: Dr. Suprava Patel, Assistant Professor, Department of Biochemistry, All India Institute of Medical Sciences (AlIMS), Raipur, Chhattisgarh-492 099, India, Tel: +918518881707; E-mail: dr_suprava@yahoo.co.in

Received October 30, 2015; Accepted December 07, 2015; Published December 11, 2015

Citation: Patel S, Nanda R, Sahoo S (2015) Nanotechnology in Healthcare: Applications and Challenges. Med chem 5: 528-533. doi: 10.4172/21610444.1000312

Copyright: ( 2015 Patel S, et al. This is an open-access article distributed under the terms of the Creative Commons Attribution License, which permits unrestricted use, distribution, and reproduction in any medium, provided the original author and source are credited. 
Citation: Patel S, Nanda R, Sahoo S (2015) Nanotechnology in Healthcare: Applications and Challenges. Med chem 5: 528-533. doi: 10.4172/21610444.1000312

\begin{tabular}{|c|c|c|}
\hline Nanomaterial & Use and its Principle & References \\
\hline Graphene oxide & Detect very low level of cancer cells (3-5 cancer cells $/ \mathrm{ml}$ blood) & Yoon et al. [5] \\
\hline Single-walled Carbon nanotubes (SWNT) & $\begin{array}{l}\text { Monitor blood nitric oxide level in inflammatory diseases. } \\
\text { It uses the principle of fluorescent signal }\end{array}$ & Iverson et al. [6] \\
\hline $\begin{array}{l}\text { Silver based nanoparticle and Raman dye-labeled DNA } \\
\text { hairpin probes }\end{array}$ & $\begin{array}{l}\text { Targets specific markers in infections. Uses the principle of SERS (surface - } \\
\text { enhanced Raman Scattering) }\end{array}$ & Wang et al. [7] \\
\hline $\begin{array}{l}\text { Nanoflares (first genetic based approach for detecting cancer } \\
\text { cells from blood) }\end{array}$ & $\begin{array}{l}\text { Enable live cell detection of intracellular mRNA. It is based on the principle of } \\
\text { fluorescence. }\end{array}$ & Halo et al. [8] \\
\hline $\begin{array}{l}\text { Iron oxide nanoworm particles coated with proteases } \\
\text { (matrixmetalloproteases, cathepsins) for early detection of } \\
\text { cancer }\end{array}$ & $\begin{array}{l}\text { It can home to a tumor and interact with cancer proteins to produce thousand of } \\
\text { biomarkers which can be detected in patient's urine by mass spectrometry. }\end{array}$ & Kwong et al. [9] \\
\hline Target specific magnetic nanoparticles & $\begin{array}{l}\text { It allows real-time monitoring the glioblastoma multiforme microvesicles in blood. The } \\
\text { are detected by a miniaturized, hand-held device. }\end{array}$ & Shao et al. [10] \\
\hline $\begin{array}{l}\text { NanoVelcro chip - anti-EpCAM antibody coated silicon } \\
\text { nanowwires overlaid with polydimethylsiloxane }\end{array}$ & $\begin{array}{l}\text { To detect and isolate the circulating tumor cells. It utilizes the principle of laser micro- } \\
\text { dissection (LMD). }\end{array}$ & Lu et al. [11] \\
\hline Silver nanorod array substrate & $\begin{array}{l}\text { On-chip separation and detection of biological agents like bacteria and viruses } \\
\text { in blood, urine, saliva and food. It uses the principle of surface enhanced Raman } \\
\text { spectroscopy (SERS). }\end{array}$ & Negri et al. [12] \\
\hline Gold nanoparticles coated with influenza A specific antibodies. & $\begin{array}{l}\text { To detect the influenza virus in sample. It is based on the principle of dynamic light } \\
\text { scattering (DLS). }\end{array}$ & Driskell et al. [13] \\
\hline $\begin{array}{l}\text { Gold nanoparticles modified with monoclonal anti- } \\
\text { hemagglutinin antibody }(\mathrm{mAb})\end{array}$ & $\begin{array}{l}\text { For detection of influenza A virus in blood. It utilizes the principle of colorimetric } \\
\text { immunosensing. }\end{array}$ & Liu et al. [14] \\
\hline Nanoparticles that form clumps & $\begin{array}{l}\text { To detect presence of cancer biomarker like Prostate specific antigen and viral } \\
\text { markers like p24 in low HIV viral load. }\end{array}$ & $\begin{array}{l}\text { de la Rica et al. } \\
{[15]}\end{array}$ \\
\hline $\begin{array}{l}\mu Q L I D A \text { (microfabricated Quantum dot-linked immune- } \\
\text { diagnostic assay) }\end{array}$ & $\begin{array}{l}\text { In-vitro diagnostic test for detecting nanomolar concentration of myelopeoxidase } \\
\text { (MPO). It is an economic and fast detecting immunofluorescence sensor with the } \\
\text { capability of } 2 \mu \mathrm{l} \text { of analyte solution and detecting nanomolar concentration of MPO } \\
\text { or other analytes. }\end{array}$ & Yu et al. [16] \\
\hline Silicon quantum dots and fluorescent nanodiamonds & $\begin{array}{l}\text { These are ultra-stable, biocompatible and nontoxic luminescent nanoprobes. It can } \\
\text { be an ideal diagnostic tool for long-term bioimaging and also a non-toxic vector for } \\
\text { drug delivery. }\end{array}$ & Montalti et al. [17] \\
\hline $\begin{array}{l}\text { Iron-oxide magnetic nanoparticles coated with peptide (poly- } \\
\text { dopamine) }\end{array}$ & $\begin{array}{l}\text { To locate cancerous cells clusters during Magnetic Resonance Imaging (MRI) and } \\
\text { photothermal cancer therapy using near-infrared laser irradiation. }\end{array}$ & Wu et al. [18] \\
\hline $\begin{array}{l}{\left[{ }^{18} \mathrm{~F}\right]-\mathrm{FAC} \text { family of positron emission tomography imaging }} \\
\text { agents }\end{array}$ & $\begin{array}{l}\text { Tumors responsive to chemotherapeutic drugs appear as bright images in PET } \\
\text { scans. }\end{array}$ & Braas et al. [19] \\
\hline Nano-MRI agent & Bind to $a_{v} \beta_{3}$-integrin found on the surface of newly developing blood vessels & Liu et al. [20] \\
\hline Gold nanoparticle based molecular diagnostic platform & $\begin{array}{l}\text { Under FDA approved nanosensor for genetic test for warfarin sensitivity. It allows } \\
\text { testing for other genetic targets }\end{array}$ & Lefferts et al. [21] \\
\hline
\end{tabular}

Table 1: Nanomaterials used in biosensing of analytes for early diagnosis of specific diseases.

\section{Nanomaterial}

Biomimetic nanosponge

Nano-composite film of carbon nanotubes (CNTs)

Gold/Bismuth based nanoparticles

Poly(ethylene oxylated) single-walled carbon nanotubes

SWNT functionalized with HER2 antibody

GRGDS-NPs (copolymer of poly(lactic-co-glycolic acid) and poly- $\varepsilon-L-l y s i n$ with polyethylene glycol terminated with arginine-glycine-aspartic acid) based targeting ligands

Fidgetin-like 2 (FL2) small interfering RNA (siRNA) nanoparticles

Fullerene nanoparticles

Carbon nanotube based nanofiber scaffold

Thymosin $\beta 4$ coated poly ( $\varepsilon$-caprolactone) nanoscaffolds

BIND-014, a prostate specific membrane antigen (PSMA)targeted NP containing docetaxel

siRNA encapsulated in a cyclodextrin based nanoparticle

Gelatin nanoparticles as acarrier for osteopontin (OPN)

Nanoparticles poly (D,L-Lactitide-co-glycolide)-(PLGA-) based polymer

Monodisperse microgels consisting of chitosan matrix, enzyme nanocapsules and recombinant human insulin

Nanocrystalline silver

Bioreducible polycations-polymer of Polyethylenimine (PE

\section{Use and its Principle}

For detoxification treatment

For non-invasive ultrasound therapy. It converts light to sound and generate high

pressure sound waves to disrupt cells. It is also called 'Invisible knife for non- Baac et al. [24] invasive therapy.

To concentrate radiation used in radiation therapy to treat cancer tumors.

Maintains brains blood circulation.

For selective destruction of breast cancer cells

\section{References}

Hu et al. [23]
Cooper et al. [25]

These are novel hemostatic NPs administered intravenously to activates the clotting process and reduce bleeding due to trauma.

FL2, the regulator of cell migration is targeted by the nanoparticle encapsulated siRNA, to promote wound closure and regeneration.

Reduce allergic reactions

Cardiac tissue engineering

Alqathami et al. [26]

Bobadilla et al. [27]

The coated nanoscaffolds, stimulates growth and differentiation of cardiomyocytes into functioning cardiac tissue and thus have potential for cardiac replacement after Oh et al. [32] any cardiac event.

Used in chemotherapy naïve metastatic castrate with refractory solid tumors

Kumar et al. [33]

To inhibit the key enzyme production in cancer cells

Given intranasally for treatment of ischemic stroke

Mita et al. [34]

Davis et al. [35]

Kanasty et al. [36]

Carrier for insulin delivery in diabetic patients

Joachim et al. [37]

sugar level in type 1 diabetes mellitus.

Antimicrobial agent for treatment of wounds

Verma et al. [38]

Gu et al. [39]

Table 2: Nanomaterials used for clinical therapy in various diseases. 
neighboring healthy tissues. The therapeutic modality is now being shifted towards intracellular molecular targets rather than the cell itself. Intracellular delivery of such gene-encoding DNAs, gene- silencing small interfering RNAs or recombinant proteins can be achieved by utilizing biocompatible packing materials. The packaging scaffold usually used are liposomes or bacterial toxins or viral NPs, but usually they get degraded and cleared off early from the circulation or may not reach to the potential target site. Recent developments in bioreducible polymers have gained more attention in as they are amenable to molecular programming through sensors that can respond to the changes in ion concentrations in the micro- environment and thus can differentiate between extracellular and intracellular sites [22].

\section{Tissue growth and regenerative medicine}

Researches in tissue regenerative medicine aims in developing implants or scaffolds capable for delivering drugs, growth factors, hormones for tissue repair. They provide sustained delivery of bioactive molecules to support survival, infiltration and proliferation of cells for tissue engineering. The expected outcome of such treatment modality is to have complete tissue replacement and functional recovery. Extracellular matrix formation is enhanced by using CNT, nanowires and nanoparticles. Biomimetic hydrogels are used as controlled biomolecule delivery of growth factors to expedite bone regeneration [40-42]. The nanofilled composites provide better compressibility, tensile strength and flexure strength compared to traditional composite microparticles. Crosslink agent composed of partially hydrolyzed polyacrylamide (HPAM) and nanocrystalline hydroxyapatite (nHAp) can be a novel scaffold for osteochondral repair [43]. Chodritin sulfate nanoparticles (CSnps) within the scaffold of chitin blended with poly(butylenes succinate) have been used for skin repair in wounds [44]. It provides superior aesthetic sense as it is biodegradable, biocompatible and forma a porous layer for better nutrient exchange. Polyethylene glycol-based hydrogel scaffold are aid in retention and growth of transplanted heart cells in myocardial infarction [45]. Glass slide coated with garphene oxide film stimulate the adhesion and osteogenic differentiation of human adipose-derived stem cells [46]. Collagen, chondroitin-6-sulfate, chitosan and laminin matrix, together have been demonstrated to support islet function invitro and allow islet survival and post-transplantation vascularization [47]. Systemic understanding of the interaction between the cells and the in-vivo microenvironment at nanoscale level can abet for better designing and fabrication of biomimetic scaffolds.

\section{Toxic Outcomes of Nanostructures}

Nanotechnology is now regarded the double edged sword. One edge depicts for potential health benefits and the other for potential health risks. Nanotechnology provides numerous advantages such as high performance, reduced size, mass and power consumption, POC testing and improved reliability and robustness. In order to explore the characteristic physicochemical properties of these nanostructures, the toxicity aspect is overlooked. They elicit unique and unpredictable biological responses, as discussed below, because of their tunable properties.

\section{Size, shape and surface area of the nanomaterial}

Because of their nanoscale size, these particles are easily accessible to the vital cells and organs. They interact with the host cell and remain adhered to the surface or internalize by translocation or by receptor mediated endocytosis. Intracellularly also they may alter the cellular metabolism by interacting with the subcellular organelles. The surface area 'o' the particle increases with decrease in particle size and the ratio of surface to total atoms or molecules increases exponentially as the particle size decreases. Ivask et al. had explained about "size-dependent: biological effects of silver NPs. In his study, silver NPs of $<10 \mathrm{~nm}$ in comparison to NPs $>10 \mathrm{~nm}$, proved to be more toxic because of their higher intracellular bioavailability [48].

Shape dependent toxicity has also been reflected in different studies based on carbon nanotubes, nanorods, nanospheres, silicas, copper, gold and many more. In a comparative study of copper oxide $(\mathrm{CuO})$ nanorods to $\mathrm{CuO}$ nanospheres by Kennedy et al. results indicated that the higher surface area of nanorods released more ions and therefore more toxic [49]. Yet optimizing the synthetic methodology, unique properties may be enhanced with minimal adverse reactions. Almodarresiyeh et al. in their studies devised a new methodology to synthesize rod-like zincoxide $(\mathrm{ZnO})$ nanoparticles in presence of polymers (polyethylenimine and hexamethylenetetramine). These NPs of $\mathrm{ZnO}$ have a wide band gap semiconductor with large excitation energy that favors its suitability to be used in optoelectronic devices [50-52].

\section{Solubility of NPs in the biological media}

The solubility of the nanomaterials in a medium is affected by its particle dispersion and agglomeration state, which in turn is influenced by its size and surface ratio. Thus the reciprocal action between the particle and its solvent also a determining factor for toxicity of NPs. Hamilton et al. illustrated the greater toxic effect of longer $\mathrm{TiO}_{2}$ nanofibers $(15 \mathrm{~mm})$ in comparison to shorter fibers because the longer fibres are insoluble in lung fluids and remain in lungs for longer time which initiates inflammatory response by the alveolar macrophages [53].

Yang et al. reported in his study that silver NPs dissolved in lower ionic strength resulted in greater toxicity than the same NPs in a higher ionic strength [54]. $\mathrm{TiO}_{2}$ or $\mathrm{ZnO}$ exhibits different diameters in different biological milieu and thus toxicity differs accordingly.

\section{Surface chemistry (charge/surface coatings)}

Surface charge of a NP is also a major determinant factor for its interaction with the biological environment. As per Dejaguin-LandauVerwey-Overbeek (DLVO) theory, stability of particles is determined by the net electrostatic surface interactions of the particles and the Van der Waals forces. As depicted in a study by Stebounova et al. polymercoated silver NPs with higher surface charge were more stable than the silver NPs with unspecified coatings in simulated lung fluid [55]. Park et al. suggested that negatively charged silica $\left(\mathrm{SiO}_{2}\right) \mathrm{NPs}$ had more toxic effect compared to weakly negatively charged silica NPs. Articles have revealed significant cellular uptake of positively charged $\mathrm{SiO}_{2}$ owing to their enhanced opsonisation by plasma proteins. $\mathrm{SiO}_{2}$ also induce intracellular reactive oxygen species (ROS) generations and exert their toxic effect by oxidative stress [56].

\section{Composition and degree of purity}

Nanomaterials are composed of heavy metals with known toxicity such as Cadmium Selenide (CdSe) NPs are toxic to rat liver and renal cells [57], carbon based NPs cause lung tumors [58] and iron containing NPs are toxic to nerve cells [59].

Liu et al. in their study provided evidences for genotoxic and cytotoxic effects of cadmium sulfide (CdS) on renal cells, liver cells, spermatozoon and tested organs [57].

Harper et al. assessed the impact of synthesis method and purity on the biocompatibility of peptide-capped gold-glutathione (Au-GSH) NPs. The study displayed significant morbidity and mortality for AuGSH-(Trp) ${ }_{2}$ purified by dialysis. The toxic effects were also significant 
for Au-GSH-(His), synthesized by either dialysis or ultracentrifugation whereas Au-GSH-(Met) ${ }_{2}$ manifested least toxicity. A prudent synthesis protocol can yield high degree purity for NPs and show improved biocompatibility [60].

\section{Aspect ratio dependent toxicity}

It is seen that toxicity is directly proportional to the aspect ratio (ratio of highest to the lowest dimension considered the particles are of similar size). NPs with high aspect ratio include nanotubes, nanowires and nanorods whereas low aspect ratio seen in spherical, oval, cubic forms [61]. Asbestos fibers longer than 10 microns cause lung cancer, those of 5 micron size lead to mesothelioma in lungs whereas fibers of 2 microns with asbestosis. The longer asbestos fibers are degraded perpendicularly and made shorter and cleared by the macrophages. Smaller fibers are cut longitudinally generating more of smaller diameter fibres which are more difficult to be removed. However slow clearance of degraded particles would lead to accumulation of the longer fibers in the alveoli inducing inflammatory changes. Long aspect ratio of SWCNT has been signoificantly associated with pulmonary toxicity when compared to the spherical amorphous carbon black particles [62].

\section{Aggregation state of NPs}

Aggregation is an ubiquitous phenomenon among all NPs and mediate cellular uptake of bio-molecules. Albanese et al. investigated uptake of transferrin-coated gold NP aggregate on different cell lines. The aggregates reduced the uptake via receptor-mediatedendocytosis in HeLa and A549 cells. In contrast, foe MDA-MB-435 cells, the aggregates internalized independent of transferring receptor via unknown mechanism. The study predicted that NP aggregate bring about multiple cellular responses [63]. Tripathy et al. demonstrated about the effects of particle size and aggregation of $\mathrm{ZnO}$ nanoparticles. Smaller aggregates tend to have higher dissolution rate and cellular uptake resulting in ROS generation and induction of cellular apoptosis [64].

\section{Antigenicity of NPs}

Nanoparticles can be antigenic themselves and the immunogenicity depends on their physicochemical properties. They can be opsonized by plasma proteins and result in activation of complement cascade. As reported by Trynda-Limiesz et al. nab-paclitaxel in pigs evoked immunological type of response when compared to albumin control [65]. Abrams et al. documented that liposomal siRNA delivery vehicle LNP201 induced cytokine release (cytokine storm) typical of unregulated innate immune response [66].

\section{Challenges for Nanotechnology}

Although nanotechnology is a very rapidly growing field, still the product availability is far away from reach because of various hurdles at different stages of development. The barriers for growth, as enumerated below, if overcome can bring about revolutionary changes in the field of health care and medicine.

\section{Lack of knowledge NP components and their characteristics}

There are numerous varieties of nanostructures, with different compositions and actions. The in-vitro and in-vivo physicochemical phenomenon of these NPs are not well understood. Hence identifying the right nanomaterial for the intended indication is crucial. PEI is being recognized as an excellent cargo for intracellular nucleic acid targeting. Nonetheless, it is also regarded as a significant cytotoxic agent. Owing to its higher proficiency in drug delivery, methods have been devised to reduce its toxicity by crosslinking low molecular weight PEI to dithiodipropionic acid di(N-succinimidyl ester) [22].

\section{Lack of uniformity of toxicity}

Nanomaterials of different composition, size or shape may be toxic to a different set of cells at different set of exposure conditions. The target cell and the target moieties for toxicity varies with the composition, size, shape, charge, aggregation, coating and solubility of nanoparticles. CNTs at $400 \mu \mathrm{g} / \mathrm{ml}$ are cytotoxic to human T-cells, 3.06 $\mu \mathrm{g} / \mathrm{cm}^{2}$ on alveolar macrophages whereas cell cultures exposed to 3.8 $\mu \mathrm{g} / \mathrm{ml}$ do not reveal any cytotoxicity [22].

\section{Lack of standardization in model systems and test assay}

There is no good in vivo model to elucidate the physical, chemical and biological behavior precisely. It is difficult to validate the results of interplay of NPs with cells as the outcome varied with different set of cells even if the test assay conditions remain same.

\section{Lack of standard synthesis protocol}

Production of nanomaterials utilizes numerous synthetic reagents which are also toxic. Efficient synthetic pathway must be developed with avoidance to use of precarious pollutants. Prudent use of synthetic material and comply with safety guidelines can ensure for yield of high purity and better biocompatible nanoparticle.

\section{Lack of efficient analytical tools}

Nanotechnology deals with nanoscale structures, hence novel analytical methods need to be developed to acquire the nanomaterial description precisely such as particle size, surface charge, surface chemistry, crystalline state, aggregation state and its distribution. New innovations in metrological technology requisite to predict the behavior of nanoparticle in biological media.

\section{Lack of understanding of impact on biological system}

Impact on health and safety issues still unclear in terms of cellular or organ toxicity, genotoxic or carcinogenic. These materials are small enough to be inhaled and the particles accumulate in lung alveoli to induce inflammatory changes or carcinogenic effect. This would be of prime concern because the workers will be under threat of occupational hazard.

\section{Lack of in-vivo monitoring systems}

Substantial infrastructure for in-vivo analysis of the nanomedicines, inability to monitor multiple probes and patients need to be admitted for analysis, are the major factors that preclude optimization of the biological activities.

\section{Lack of standardized safety guidelines}

Due to complex nature of nanomedicines and their multiform toxicity, it is difficult to outline a particular safety guideline for a particular nanoparticle. To provide a safety protocol, empirical evidence and extensive pre-clinical testing is mandatory.

\section{Lack of well trained workforce}

High energy consumption due to which production cost is very high and restricted accessibility to people. This is a major hindrance for the goal to be achieved for POC testing to the remote areas.

It is the need of the hour to ensue towards efficient production of nanostructures 'Safe by Design', through green chemistry, optimizing standard protocols for synthesis, production and clinical testing. In shaping of 'Green Nanotechnology', contribution and involution of scientific personnels, persons from governmental sector, industrial and workforce representatives is required in order to modulate the 
set of rules so that the occupational and health promotional benefits outweighs the cost and risk factors [67].

\section{Conclusion}

Nanotechnology offers the ability to build large numbers of products that are incredibly powerful. Nanomedicines and nanodevices are in their early stages of development. The development processes are heavily interwined with biotechnology and information technology, making its scope very wide. Nanotechnology based products are capable of overcoming the limitations of traditional methods. But, the major challenges are yet to prevail over its toxicity, environmental hazards, production cost and accessibility to the un-reachable at far-off areas.

\section{References}

1. Morrison D, Dokmeci M, Demirci U, Khademhosseini A (2008) "Biomedical Nanostructures" ed. by Kenneth G, Craig H, Cato TL, Lakshmi N. John Wiley \& Sons, Inc.

2. Rocco M, Williams S, Alivisato $P$ (2000) Nanotechnology Research Directions: IWGN, Loyola College in Maryland, "National Nanotechnology Initiative: Leading to the next Industrial Revolution," A report by the Interagency Working Group on Nanoscience, Engineering and Technology Committee on Technology, National Science and Technology Council, Washington, DC.

3. Mansoori GA, Soelaiman TAF, Soelaiman TAF (2005) Nanotechnology-An Introduction for the Standards Community. J ASTM Int 2: 1-22.

4. Feynman R (1993) Infinitesimal Machinery. Lecture reprinted in the Journal of Microelectromechanical Systems.

5. Yoon HJ, Lee K, Zhang Z, Pham TM, Nagrath S (2011) Nanoassembly of graphene oxide for circulating tumor cell isolation.

6. Iverson NM, Barone PW, Shandell M, Trudel LJ, Sen S, et al. (2013) In vivo biosensing via tissue-localizable near-infrared-fluorescent single-walled carbon nanotubes. Nat Nanotechnol 8: 873-880.

7. Wang HN, Fales AM, Zaas AK, Woods CW, Burke T, et al. (2013) Surfaceenhanced Raman scattering molecular sentinel nanoprobes for viral infection diagnostics. Anal Chim Acta 786: 153-158.

8. Halo TL, McMahon KM, Angeloni NL, Xu Y, Wang W, et al. (2014) NanoFlares for the detection, isolation, and culture of live tumor cells from human blood. Proc Natl Acad Sci USA 111: 17104-17109.

9. Kwong GA, von Maltzahn G, Murugappan G, Abudayyeh O, Mo S, et al. (2012) Mass- encoded synthetic biomarkers for multiplexed urinary monitoring of disease. Nat Biotechnol. 31: 63-70.

10. Shao H, Chung J, Balaj L, Charest A, Bigner DD, et al. (2012) Protein typing of circulating microvesicles allows real-time monitoring of glioblastoma therapy. Nat Med 18: 1835-1840.

11. Lu YT, Zhao L, Shen Q, Garcia MA, Wu D, et al. (2013) NanoVelcro Chip for CTC enumeration in prostate cancer patients. Methods 64: 144-152.

12. Negri P, Dluhy RA (2013) Ag nanorod based surface-enhanced Raman spectroscopy applied to bioanalytical sensing. J Biophotonics 6: 20-35.

13. Driskell JD, Jones CA, Tompkins SM, Tripp RA (2011) One-step assay for detecting influenza virus using dynamic light scattering and gold nanoparticles. The Analyst 136: 3083-3090.

14. Liu Y, Zhang L, Wei W, Zhao H, Zhou Z, et al. (2015) Colorimetric detection of influenza $A$ virus using antibody-functionalized gold nanoparticles. Analyst 140: 3989-3995

15. de la Rica R, Stevens MM (2012) Plasmonic ELISA for the ultrasensitive detection of disease biomarkers with the naked eye. Nat Nanotechnol 7: 821-824.

16. Yu C, Kim GB, Clark PM, Zubkov L, Papazoglou ES, et al. (2015) A microfabricated quantum dot-linked immuno-diagnostic assay ( $\mu$ QLIDA) with an electrohydrodynamic mixing element. Sens Actuators B Chem 209: 722-728.

17. Montalti M, Cantelli A, Battistelli G (2015) Nanodiamonds and silicon quantum dots: ultrastable and biocompatible luminescent nanoprobes for long-term bioimaging. Chem Soc Rev 44: 4853-4921.

18. Wu M, Zhang D, Zeng Y, Wu L, Liu X, et al. (2015) Nanocluster of superparamagnetic iron oxide nanoparticles coated with poly (dopamine) for magnetic field-targeting, highly sensitive MRI and photothermal cancer therapy. Nanotechnology 26: 115102.
19. Braas D, Ahler E, Tam B, Nathanson D, Riedinger M, et al. (2012) Metabolomics strategy reveals subpopulation of liposarcomas sensitive to gemcitabine treatment. Cancer Discov 2: 1109-1117.

20. Zhang C, Liu Y (2013) A concise review of magnetic resonance molecular imaging of tumor angiogenesis by targeting integrin $\alpha v \beta 3$ with magnetic probes. Int J Nanomedicine 8: 1083-1093.

21. Lefferts JA, Schwab MC, Dandamudi UB, Lee HK, Lewis LD, et al. (2010) Warfarin genotyping using three different platforms. Am J Transl Res 2: 441-446.

22. Klein PM, Wagner E (2014) Bioreducible Polycations as Shuttles for Therapeutic Nucleic Acid and Protein Transfection. Antioxid Redox Signal 21: 804-817.

23. Hu CMJ, Fang RH, Copp J, Luk BT, Zhang L (2013) A biomimetic nanosponge that absorbs pore-forming toxins. Nat Nanotechnol 8: 336-340.

24. Baac HW, Ok JG, Maxwell A, Lee KT, Chen YC, et al. (2012) Carbon-nanotube optoacoustic lens for focused ultrasound generation and high-precision targeted therapy. Sci Rep 2: 989.

25. Cooper DR, Bekah D, Nadeau JL (2014) Gold nanoparticles and their alternatives for radiation therapy enhancement. Front Chem 2: 86.

26. Alqathami M, Blencowe A, Yeo UJ, Franich R, Doran S, et al. (2013) Enhancement of radiation effects by bismuth oxide nanoparticles for kilovoltage x-ray beams: A dosimetric study using a novel multi-compartment 3D radiochromic dosimeter. J Phys Conf Ser 444: 012025.

27. Bobadilla AD, Samuel ELG, Tour JM, Seminario JM (2013) Calculating the Hydrodynamic Volume of Poly(ethylene oxylated) Single-Walled Carbon Nanotubes and Hydrophilic Carbon Clusters. J Phys Chem B 117: 343-354.

28. Xiao Y, Gao X, Taratula O, Treado S, Urbas A, et al. (2009) Anti-HER2 IgY antibody- functionalized single-walled carbon nanotubes for detection and selective destruction of breast cancer cells. BMC Cancer 9: 351.

29. Shoffstall AJ, Atkins KT, Groynom RE, Varley ME, Everhart LM, et al. (2012) Intravenous Hemostatic Nanoparticles Increase Survival Following Blunt Trauma Injury. Biomacromolecules 13: 3850-3857.

30. Charafeddine RA, Makdisi J, Schairer D, O'Rourke BP, Diaz-Valencia JD, et al. (2015) Fidgetin-Like 2: A Microtubule-Based Regulator of Wound Healing. J Invest Dermatol 135: 2309-2318.

31. Ryan JJ, Bateman HR, Stover A, Gomez G, Norton SK, et al. (2007) Fullerene nanomaterials inhibit the allergic response. J Immunol 179: 665-672.

32. Oh B, Lee CH (2013) Nanofiber for cardiovascular tissue engineering. Expert Opin Drug Deliv 10: 1565-1582.

33. Kumar A, Patel A, Duvalsaint L, Desai M, Marks ED (2014) Thymosin B4 coated nanofiber scaffolds for the repair of damaged cardiac tissue. J Nanobiotechnology 12: 10.

34. Mita M, Burris H, LoRusso P, Hart L, Eisenberg P, et al. (2014) Abstract CT210 A phase 1 study of BIND-014, a PSMA-targeted nanoparticle containing docetaxel, administered to patients with refractory solid tumors on a weekly schedule. Cancer Res 74 (19 Supplement): CT210-CT210.

35. Davis ME (2009) The first targeted delivery of siRNA in humans via a selfassembling, cyclodextrin polymer- based nanoparticle: from concept to clinic Mol Pharm 6: 659-668.

36. Kanasty R, Dorkin JR, Vegas A, Anderson D (2013) Delivery materials for siRNA therapeutics. Nat Mater 12: 967-977.

37. Joachim E, Kim ID, Jin Y, Kim KK, Lee JK, et al. (2014) Gelatin nanoparticles enhance the neuroprotective effects of intranasally administered osteopontin in rat ischemic stroke model. Drug Deliv Transl Res 4: 395-399.

38. Verma A, Kumar N, Malviya R, Sharma PK, Verma A, et al. (2014) Emerging Trends in Noninvasive Insulin Delivery, Emerging Trends in Noninvasive Insulin Delivery. J Pharm J Pharm 2014: e378048.

39. Gu Z, Dang TT, Ma M, Tang BC, Cheng H, et al. (2013) Glucose-responsive microgels integrated with enzyme nanocapsules for closed-loop insulin delivery. ACS Nano 7: 6758-6766.

40. Fong J, Wood F (2006) Nanocrystalline silver dressings in wound management: a review. Int J Nanomedicine 1: 441-449.

41. Oupicky D, Li J (2014) Bioreducible polycations in nucleic acid delivery: past present, and future trends. Macromol Biosci 14: 908-922.

42. Lienemann PS, Lutolf MP, Ehrbar M (2012) Biomimetic hydrogels for controlled biomolecule delivery to augment bone regeneration. Adv Drug Deliv Rev 64 1078-1089. 
Citation: Patel S, Nanda R, Sahoo S (2015) Nanotechnology in Healthcare: Applications and Challenges. Med chem 5: 528-533. doi: 10.4172/21610444.1000312

43. Koushki N, Katbab AA, Tavassoli H, Jahanbakhsh A, Majidi M, et al. (2015) A new injectable biphasic hydrogel based on partially hydrolyzed polyacrylamide and nanohydroxyapatite as scaffold for osteochondral regeneration. RSC Adv 5: 9089-9096.

44. Deepthi S, Viha CVS, Thitirat C, Furuike T, Tamura H, et al. (2014) Fabrication of Chitin/Poly(butylene succinate)/Chondroitin Sulfate Nanoparticles Ternary Composite Hydrogel Scaffold for Skin Tissue Engineering. Polymers 6: 29742984.

45. Grover GN, Rao N, Christman KL (2014) Myocardial Matrix-Polyethylene Glycol Hybrid Hydrogels for Tissue Engineering. Nanotechnology 25: 014011.

46. Lyu CQ, Lu JY, Cao CH, Luo D, Fu YX, et al. (2015) Induction of Osteogenic Differentiation of Human Adipose-Derived Stem Cells by a Novel SelfSupporting Graphene Hydrogel Film and the Possible Underlying Mechanism. ACS Appl Mater Interfaces 7: 20245-20254.

47. Ellis CE, Suuronen E, Yeung T, Seeberger K, Korbutt GS (2013) Bioengineering a highly vascularized matrix for the ectopic transplantation of islets. Islets 5 : 216-225.

48. Ivask A, Kurvet I, Kasemets K, Blinova I, Aruoja V, et al. (2014) Size-dependent toxicity of silver nanoparticles to bacteria, yeast, algae, crustaceans and mammalian cells in vitro. PLoS One 9: e102108.

49. Kennedy AJ, Melby NL, Moser RD, Bednar AJ, Son SF, et al. (2013) Fate and toxicity of $\mathrm{CuO}$ nanospheres and nanorods used in $\mathrm{Al} / \mathrm{CuO}$ nanothermites before and after combustion. Environ Sci Technol 47: 11258-11267.

50. Almodarresiyeh HA, Abakshonok AV, Agabekov VE, Eryomin AN (2014) Synthesis of $\mathrm{ZnO}$ nanoparticles from different zinc salts/Civilica: encycl. of civil engineering.

51. Almodarresiyeh HA, Abakshonok AV, Agabekov VE, Eryomin AN, Shahab SN (2014) Investigation of reaction conditions on morphology and optical properties of Zinc Oxide Nanorods. In: IOP Conference Series: Materials Science and Engineering [Internet]. IOP Publishing 012050.

52. Almodarresiyeh HA, Filippovich L, Shahab SN, Ariko N, Agabekov VE (2014) Polyvinyl alcohol films modified by organic dyes and zinc oxide nanoparticles/ The international conference science and applications of thin films, SATF, Izmir, Turkey.

53. Hamilton RF, Wu N, Porter D, Buford M, Wolfarth M, et al. (2009) Particle length-dependent titanium dioxide nanomaterials toxicity and bioactivity. Part Fibre Toxicol 6: 35

54. Yang X, Gondikas AP, Marinakos SM, Auffan M, Liu J, et al. (2012) Mechanism of silver nanoparticle toxicity is dependent on dissolved silver and surface coating in Caenorhabditis elegans. Environ Sci Technol 46: 1119-1127.
55. Stebounova LV, Adamcakova-Dodd A, Kim JS, Park H, O'Shaughnessy PT, et al. (2011) Nanosilver induces minimal lung toxicity or inflammation in a subacute murine inhalation model. Part Fibre Toxicol 8: 5.

56. Park YH, Bae HC, Jang Y, Jeong SH, Lee HN, et al. (2013) Effect of the size and surface charge of silica nanoparticles on cutaneous toxicity. Mol Cell Toxicol 9: 67-74.

57. Liu L, Sun M, Li Q, Zhang H, Alvarez PJJ, et al. (2014) Genotoxicity and Cytotoxicity of Cadmium Sulfide Nanomaterials to Mice: Comparison Between Nanorods and Nanodots. Environ Eng Sci 31: 373-380.

58. Guo NL, Wan YW, Denvir J, Porter DW, Pacurari M, et al. (2012) Multiwalled carbon nanotube-induced gene signatures in the mouse lung: potential predictive value for human lung cancer risk and prognosis. J Toxicol Environ Health A75: 1129-1153.

59. Wu J, Ding T, Sun J (2013) Neurotoxic potential of iron oxide nanoparticles in the rat brain striatum and hippocampus. Neurotoxicology 34: 243-253.

60. Harper B, Sinche F, Wu RH, Gowrishankar M, Marquart G, et al. (2014) The Impact of Surface Ligands and Synthesis Method on the Toxicity of GlutathioneCoated Gold Nanoparticles. Nanomater Basel Switz 4: 355-371.

61. Buzea C, Pacheco Blandino I, Robbie K (2007) Naomaterials and nanoparticles: sources and toxicity.

62. Shvedova AA, Kisin ER, Mercer R, Murray AR, Johnson VJ, et al. (2005) Unusual inflammatory and fibrogenic pulmonary responses to single-walled carbon nanotubes in mice. Am J Physiol Lung Cell Mol Physiol 289: L698-708.

63. Albanese A, Chan WC (2011) Effect of gold nanoparticle aggregation on cel uptake and toxicity. ACS Nano 5: 5478-5489.

64. Tripathy N, Hong TK, Ha KT, Jeong HS, Hahn YB (2014) Effect of ZnO nanoparticles aggregation on the toxicity in RAW 264.7 murine macrophage. J Hazard Mater 270C: 110-117.

65. Desai $N$ (2012) Challenges in development of nanoparticle-based therapeutics AAPS J 14: 282-295.

66. Abrams MT, Koser ML, Seitzer J, Williams SC, DiPietro MA, et al. (2010) Evaluation of Efficacy, Biodistribution, and Inflammation for a Potent siRNA Nanoparticle: Effect of Dexamethasone Co- treatment. Mol Ther 18: 171-180.

67. Lynch I, Weiss C, Valsami-Jones E (2014) A strategy for grouping of nanomaterials based on key physico- chemical descriptors as a basis for saferby-design NMs. Nano Today 9: 266-270. 